\title{
Effects of Ionic Strength on Arsenate Adsorption at Aluminum Hydroxide-Water Interfaces
}

\author{
Tingying $\mathrm{Xu}$ (i) and Jeffrey G. Catalano * \\ Department of Earth and Planetary Sciences, Washington University, 1 Brookings Drive, Saint Louis, MO 63130, \\ USA; xutingying@wustl.edu \\ * Correspondence: catalano@eps.wustl.edu; Tel.: +1-314-935-6015
}

Received: 25 November 2017; Accepted: 27 December 2017; Published: 1 January 2018

\begin{abstract}
Adsorption processes at mineral-water interfaces control the fate and transport of arsenic in soils and aquatic systems. Mechanistic and thermodynamic models to describe this phenomenon only consider inner-sphere complexes but recent observation of the simultaneous adsorption of inner- and outer-sphere arsenate on single crystal surfaces complicates this picture. In this study, we investigate the ionic strength-dependence of the macroscopic adsorption behavior and molecular-scale surface speciation of arsenate bound to gibbsite and bayerite. Arsenate adsorption decreases with increasing ionic strength on both minerals, with a larger effect at $\mathrm{pH} 4$ than $\mathrm{pH}$ 7. The observed $\mathrm{pH}$-dependence corresponds with a substantial decrease in surface charge at $\mathrm{pH} 7$, as indicated by $\zeta$-potential measurements. Extended X-ray absorption fine structure (EXAFS) spectroscopy finds that the number of second shell $\mathrm{Al}$ neighbors around arsenate is lower than that required for arsenate to occur solely as an inner-sphere surface complex. Together, these observations demonstrate that arsenate displays macroscopic and molecular-scale behavior consistent with the co-occurrence of inner- and outer-sphere surface complexes. This demonstrated that outer-sphere species can be responsible for strong adsorption of ions and suggests that environments experiencing an increase in salt content may induce arsenic release to water, especially under weakly acidic conditions.
\end{abstract}

Keywords: arsenate adsorption; ionic strength; inner-sphere adsorption; outer-sphere adsorption; adsorption isotherm; EXAFS spectroscopy

\section{Introduction}

Adsorption is a critical control on the occurrence and fate of arsenic in soils and aquatic systems [1-5] and is utilized to remove this toxic element during water treatment $[6,7]$. Arsenate $\left(\mathrm{H}_{\mathrm{x}} \mathrm{AsO}_{4}{ }^{\mathrm{x}-3}\right)$, the common form of arsenic under oxidizing conditions, strongly adsorbs to many mineral surfaces, especially to aluminum and iron (oxyhydr)oxides $[1,4,8,9]$. The macroscopic uptake of this oxoanion onto oxide minerals has not been observed to display a dependence on ionic strength in prior studies [8-10], indicating a lack of outer-sphere complexes [11]. Previous spectroscopic studies have widely observed that arsenate forms inner-sphere surface complexes on mineral surfaces $[4,8,9,12-17]$. Surface complexation models for arsenate adsorption predict the partitioning of this oxoanion between water and mineral surfaces using only such complexes [9,18-20]. A description of arsenate adsorption behavior based solely on an inner-sphere (ligand exchange) binding mechanism was thus established over the last few decades that is widely accepted today.

This picture became more complicated when the simultaneous occurrence of both inner- and outer-sphere arsenate surface complexes was observed on aluminum and iron oxide single crystal surfaces [21]. While the transferability of processes on such highly-idealized surfaces to particles representative of natural and engineered sorbents is uncertain, a re-evaluation of past observations is warranted. Detection of inner-sphere complexes using extended X-ray absorption fine structure 
(EXAFS) spectroscopy does not preclude co-existing outer-sphere species, as the latter lack diagnostic features in EXAFS spectra [21]. Hydrogen bonding of outer-sphere molecules to surface functional groups may yield infrared (IR) spectra of arsenate similar to what would be expected for inner-sphere species [16]. Furthermore, macroscopic uptake of arsenate will not display a dependence on ionic strength where outer-sphere complexes are neutrally-charged or when the surface potential is near zero. Prior work with mineral powders thus often cannot unambiguously rule out the co-occurrence of outer- and inner-sphere arsenate surface complexes.

Our recent work investigating binding site effects on arsenate adsorption to $\mathrm{Al}(\mathrm{OH})_{3}$ polymorphs, gibbsite and bayerite, observed a lower coordination number of second-shell Al neighbors for gibbsite, indicating an additional surface species was present [22]. Other inner-sphere binding configurations were not present, suggesting co-occurring outer-sphere arsenate species. This molecular-scale picture conflicts with previous macroscopic studies that have not observed ionic strength-dependent arsenate adsorption behavior on aluminum and iron oxides [8-10]. Antelo et al. [10] did not detect observable changes in arsenate adsorption isotherms for goethite between 0.01 and $0.1 \mathrm{M} \mathrm{KNO}_{3}$ fluids. Goldberg and Johnston [9] observed a possible increase in adsorption with increasing ionic strength in adsorption edge measurements on amorphous iron oxide but saw no ionic strength dependence on amorphous aluminum oxide. Arai et al. [8] observed no ionic strength effect on arsenate adsorption to $\gamma-\mathrm{Al}_{2} \mathrm{O}_{3}$, but their data contains substantial scatter and high percentages of arsenate adsorption at low $\mathrm{pH}$, making detection of ionic strength effects difficult. In all cases, a substantial fraction clearly occurs as inner-sphere species based on many past spectroscopic studies $[4,8,9,12-17]$ and the ionic strength-dependence of macroscopic adsorption would be smaller in magnitude than for an ion that bind solely as an outer-sphere species. Exploration of the ionic strength dependence of arsenate adsorption to aluminum hydroxides is thus warranted given the contrasting past results.

In this study, we seek to determine whether macroscopic arsenate adsorption onto aluminum hydroxides displays a dependence on ionic strength that is consistent with our recent molecular-scale observations suggesting that inner- and outer-sphere species co-occur. Both gibbsite and bayerite are studied because they differ in morphology and thus have distinct distributions of surface functional group types [23] that may lead to a distinct ionic strength-dependence of arsenate adsorption. Adsorption isotherms were measured on both minerals at $\mathrm{pH} 4$ and 7 with ionic strength of 0.001 , $0.01,0.1$, and $0.5 \mathrm{M} \mathrm{NaNO}_{3}$. $\zeta$-potential measurements assessed the sign and relative magnitude of gibbsite and bayerite surface charge in the presence and absence of adsorbed arsenate at the different ionic strength value used for the isotherm measurements. EXAFS spectroscopy characterized arsenate adsorption mechanisms on each mineral surface at low and high arsenate surface coverages at low and high ionic strength at both $\mathrm{pH} 4$ and 7 . These macroscopic and molecular-scale studies were integrated to assess the influences of ionic strength on arsenate adsorption on aluminum hydroxide surfaces.

\section{Materials and Methods}

\subsection{Mineral and Reagent Preparation}

Gibbsite and bayerite were prepared following previously published syntheses [22], modified from the procedures described in Shen et al. [24] and Lefevre et al. [25]. After synthesis, gibbsite and bayerite were washed repeatedly in deionized water $(>18.2 \mathrm{M} \Omega \cdot \mathrm{cm})$ to remove excess electrolytes. Both minerals were resuspended in deionized water and stored in polypropylene bottles. The concentrations of the gibbsite and bayerite mineral suspensions were determined through gravimetric analysis. Both gibbsite and bayerite particles have been previously characterized by Brunauer-Emmett-Teller (BET) analysis, powder X-ray diffraction (XRD), and scanning electron microscope (SEM) [22].

Sodium nitrate $\left(\mathrm{NaNO}_{3}\right.$, Sigma Aldrich, St. Louis, MO, USA, ReagentPlus $\left.\geq 99 \%\right)$, 3-(N-morpholino) propanesulfonic acid hemisodium salt (MOPS; Sigma Aldrich, $\geq 99 \%$ ), and sodium arsenate $\left(\mathrm{Na}_{2} \mathrm{HAsO}_{4} \cdot 7 \mathrm{H}_{2} \mathrm{O}\right.$; Sigma Aldrich, ACS Reagent $\left.\geq 98 \%\right)$ stock solutions were made with deionized water. Two $20 \mathrm{~g} / \mathrm{L}$ suspensions of gibbsite and bayerite were prepared in deionized water. Experiments 
conducted at $\mathrm{pH} 7$ used a MOPS solution to buffer $\mathrm{pH}$. All $\mathrm{pH}$ adjustments were made using $\mathrm{HNO}_{3}$ or $\mathrm{NaOH}$ solutions.

\subsection{Macroscopic Arsenate Adsorption Isotherms}

Arsenate adsorption onto gibbsite and bayerite at $\mathrm{pH} 4$ and 7 at solution ionic strength of 0.001 , $0.01,0.1$, and $0.5 \mathrm{M} \mathrm{NaNO}_{3}$ were investigated by batch adsorption isotherm experiments. Samples contained $4 \mathrm{~g} / \mathrm{L}$ of gibbsite or bayerite reacted in a solution with an initial arsenate concentration from $10 \mu \mathrm{M}$ to $500 \mu \mathrm{M}$, the desired concentration of $\mathrm{NaNO}_{3}(0.001,0.01,0.1$, and $0.5 \mathrm{M})$, and, at $\mathrm{pH}$ 7, a pH buffer of $0.001 \mathrm{M}$ MOPS, added as the hemisodium salt (no buffer was used at $\mathrm{pH} 4$ ). It should be noted that the addition of MOPS hemisodium salt increases the ionic strength values to $0.0015,0.0105$, 0.1005 , and $0.5005 \mathrm{M}$ for the $\mathrm{pH} 7$ system. For each series of experiment, four mineral-free blanks with 40,100, 200, and $400 \mu \mathrm{M}$ arsenate were prepared to assess systematic errors in the initial arsenate concentrations. The samples were rotated on end-over-end rotators for $24 \mathrm{~h}$ at room temperature. During the reaction time, sample $\mathrm{pH}$ was checked and adjusted to the target values. At the end of the experiment, the samples were filtered $(0.22 \mu \mathrm{m}, \mathrm{MCE}$; Santa Cruz Biotechnology, Dallas, TX, USA), discarding the first $1 \mathrm{~mL}$ of the filtrate, and acidified to $2 \% \mathrm{HNO}_{3}$ (trace metal grade; EMD Millipore, Billerica, MA, USA). The acidified filtrates were diluted appropriately with $2 \% \mathrm{HNO}_{3}$ for inductively coupled-plasma mass spectrometry (ICP-MS, Thermo Scientific iCAP Q, Bremen, Germany) analysis for dissolved arsenate concentrations.

\section{3. ऊ-Potential Analysis}

$\zeta$-potential analysis was performed to study the electrokinetic response of gibbsite and bayerite particles to different ionic strength with and without arsenate over $\mathrm{pH}$ range of 3-8. Suspensions were prepared in the same way as the batch adsorption samples with 40 and $400 \mu \mathrm{M}$ arsenate. Samples with no arsenate were prepared as the blank references. Suspensions $(1 \mathrm{~mL})$ were withdrawn with syringes and injected into a $\zeta$-Potential analyzer (Zetasizer Nano ZS, Malvern, Southborough, MA, USA). Each data point is the average of three replicate measurements.

\subsection{EXAFS Spectroscopic Measurements}

The coordination environment of arsenate adsorbed to gibbsite and bayerite at different ionic strength was investigated with EXAFS spectroscopy. Separate batch adsorption experiments were conducted to prepare fresh samples before beamline measurements. Scaled-up reactors $(50 \mathrm{~mL}$ total volume) were used to prepare samples with sufficient solid mass for EXAFS measurements. Two adsorbed arsenate samples for each mineral at the lowest and highest background electrolyte concentrations $\left(I=0.001\right.$ and $\left.0.5 \mathrm{M} \mathrm{NaNO}_{3}\right)$ at each $\mathrm{pH}$ were prepared with initial low $(40 \mu \mathrm{M})$ and high $(400 \mu \mathrm{M})$ loading of arsenate (Table 1). All samples were centrifuged to separate the supernatant and solid (wet paste). The solids were packed as wet paste into polycarbonate sample holders, sealed with $25 \mu \mathrm{m}$ Kapton tape, and heat sealed in a polyethylene bag with a damp Kimwipe to prevent drying.

Samples were prepared within 3 days of transport to the Stanford Synchrotron Radiation Lightsource (SSRL) at the SLAC National Accelerator Laboratory for measurements of As K-edge EXAFS spectra at SSRL beamline 4-1. Beamline 4-1 uses a Si (220) double crystal monochromator, which was detuned by $35 \%$ to attenuate beam harmonics. Fluorescence yield spectra were measured using a 30-element energy-dispersive Ge detector. Energy was calibrated using a Au metal foil, with the first inflection point in the Au $\mathrm{L}_{\mathrm{III}}$-edge set to $11919 \mathrm{eV}$.

The Athena interface [26] to IFEFFIT [27], together with the SamView component of SixPack [28], were used to average, deadtime correct, and normalize the spectra. The mansfieldite $\left(\mathrm{AlAsO}_{4} \cdot 2 \mathrm{H}_{2} \mathrm{O}\right)$ structure [29] was used to calculate phase-shift and backscattering amplitude functions for structural analysis of the EXAFS spectra using FEFF 7.02 [30]. The $\mathrm{k}^{3}$-weighted EXAFS spectra were fit over a $\mathrm{k}$ range of 3.5-12.5 $\AA$ and an $\mathrm{R}$ range of $0.8-4 \AA$, with the amplitude reduction factor $\left(\mathrm{S}_{0}{ }^{2}\right)$ fixed to 1.0. All spectra for each sample were fitted using a single starting structural model consisting of As-O 
and As-Al single scattering paths and three multiple scattering paths: a triangular As-O-O path, a collinear As-O-As-O path, and a non-collinear As-O-As-O path. The parameters for these paths were determined from geometric considerations [31]. In the model fits, As-O coordination numbers were fixed at 4 and the coordination numbers of As-Al shells were allowed to vary. For the As-Al single scattering path, the Debye-Waller factor, $\sigma^{2}$, was fixed to 0.006 to reduce covariation during fitting.

Table 1. Conditions for the adsorption samples analyzed by Extended X-ray absorption fine structure (EXAFS) spectroscopy.

\begin{tabular}{|c|c|c|c|c|c|c|}
\hline Sample & Mineral & $\mathrm{pH}$ & $\begin{array}{c}\text { Desired I } \\
\left(\mathrm{mol} / \mathrm{L} \mathrm{NaNO}_{3}\right)\end{array}$ & $\begin{array}{c}{\left[\mathrm{AsO}_{4}{ }^{3}\right]_{\text {init }}} \\
(\mu \mathrm{mol} / \mathrm{L})\end{array}$ & $\begin{array}{c}{\left[\mathrm{AsO}_{4}{ }^{3}\right]_{\text {final }}} \\
(\mu \mathrm{mol} / \mathrm{L})\end{array}$ & $\begin{array}{c}\Gamma_{\mathrm{As}} \\
\left(\mu \mathrm{mol} / \mathrm{m}^{2}\right)\end{array}$ \\
\hline G1 & $4 \mathrm{~g} / \mathrm{L}$ gibbsite & 7.0 & 0.5 & 40 & 10 & 0.35 \\
\hline G2 & $4 \mathrm{~g} / \mathrm{L}$ gibbsite & 7.0 & 0.5 & 400 & 338 & 0.71 \\
\hline G3 & $4 \mathrm{~g} / \mathrm{L}$ gibbsite & 7.0 & 0.001 & 40 & 2 & 0.44 \\
\hline G4 & $4 \mathrm{~g} / \mathrm{L}$ gibbsite & 7.0 & 0.001 & 400 & 329 & 0.82 \\
\hline G5 & $4 \mathrm{~g} / \mathrm{L}$ gibbsite & 4.0 & 0.5 & 40 & 9 & 0.36 \\
\hline G6 & $4 \mathrm{~g} / \mathrm{L}$ gibbsite & 4.0 & 0.5 & 400 & 312 & 1.01 \\
\hline G7 & $4 \mathrm{~g} / \mathrm{L}$ gibbsite & 4.0 & 0.001 & 40 & 1 & 0.45 \\
\hline G8 & $4 \mathrm{~g} / \mathrm{L}$ gibbsite & 4.0 & 0.001 & 400 & 278 & 1.41 \\
\hline $\mathrm{B} 1$ & $4 \mathrm{~g} / \mathrm{L}$ bayerite & 7.0 & 0.5 & 40 & 3 & 0.63 \\
\hline B2 & $4 \mathrm{~g} / \mathrm{L}$ bayerite & 7.0 & 0.5 & 400 & 333 & 1.16 \\
\hline B3 & $4 \mathrm{~g} / \mathrm{L}$ bayerite & 7.0 & 0.001 & 40 & 2 & 0.65 \\
\hline B4 & $4 \mathrm{~g} / \mathrm{L}$ bayerite & 7.0 & 0.001 & 400 & 319 & 1.39 \\
\hline B5 & $4 \mathrm{~g} / \mathrm{L}$ bayerite & 4.0 & 0.5 & 40 & 7 & 0.63 \\
\hline B6 & $4 \mathrm{~g} / \mathrm{L}$ bayerite & 4.0 & 0.5 & 400 & 329 & 1.31 \\
\hline B7 & $4 \mathrm{~g} / \mathrm{L}$ bayerite & 4.0 & 0.001 & 40 & 1 & 0.71 \\
\hline B8 & $4 \mathrm{~g} / \mathrm{L}$ bayerite & 4.0 & 0.001 & 400 & 101 & 1.92 \\
\hline
\end{tabular}

\section{Results}

\subsection{Properties of Synthesized Materials}

The chemical and physical properties of the gibbsite and bayerite used in this research have been previously described [22]. Briefly, the gibbsite and bayerite used in this study are aluminum hydroxide polymorphs with different morphology. Both mineral particles are enclosed by basal and edge surfaces with a substantially different ratio of these two types of surfaces. Synthetic gibbsite with a platelet morphology and bayerite with a micro-rod morphology were previously estimated to have $\sim 91 \%$ of the basal (001) planes, terminated by doubly coordinated $\left(>\mathrm{Al}_{2} \mathrm{OH}\right)$ functional groups, and $\sim 94 \%$ of the edge planes, terminated by singly coordinated $\left(>\mathrm{AlOH}_{2}\right)$ functional groups, respectively [22]. The gibbsite and bayerite particles have similar surface areas $\left(21.8 \mathrm{~m}^{2} / \mathrm{g}\right.$ and $23.4 \mathrm{~m}^{2} / \mathrm{g}$, respectively) determined by BET analysis [22]. Both minerals used in this study were previously characterized by XRD and SEM, confirming they are consistent with the expected products of the published mineral synthesis methods, i.e., single phase, relatively monodispersed particles of the target mineral.

\subsection{Macroscopic Arsenate Adsorption}

The macroscopic arsenate adsorption isotherms on both minerals at each ionic strength show similar trends, with arsenate displaying greater adsorption at low $\mathrm{pH}$ and on bayerite versus gibbsite (Figure 1), consistent with our prior study [22]. The macroscopic arsenate adsorption data are then fitted using Langmuir isotherm with co-optimized maximum adsorption capacity parameters $\left(\Gamma_{\max , \mathrm{i}}\right)$ and affinity constants $\left(\mathrm{K}_{\mathrm{i}}\right)$ :

$$
\Gamma_{\text {ads }}=\sum_{\mathrm{i}=1}^{\mathrm{n}} \frac{\mathrm{K}_{\mathrm{i}} \Gamma_{\text {max }, \mathrm{i}} \mathrm{C}_{(\text {ads })}}{1+\mathrm{K}_{\mathrm{i}} \mathrm{C}_{(\text {ads })}}
$$

where $\Gamma_{\text {ads }}$ is the amount of adsorbate adsorbed, $\mathrm{C}_{(\mathrm{ads})}$ is the final adsorbate concentration in solution, $n=1$ for single Langmuir fits involving only one adsorption site, and $n=2$ for dual Langmuir fits 
involving two adsorption sites. The adsorption data are better fitted using the dual Langmuir isotherm model for both gibbsite and bayerite (Figures 1 and S1). Comparing the fitting parameters in the dual Langmuir model, the total $\Gamma_{\max }$ values $\left(\Gamma_{\max , 1}+\Gamma_{\max , 2}\right)$ of bayerite are larger than those of gibbsite at same $\mathrm{pH}$ and same ionic strength (Table 2), which could be attributed to the abundance of edge surface sites on bayerite particles displaying stronger adsorption capacity. However, under the same experimental condition, the two components $\Gamma_{\max , 1}$ and $\Gamma_{\max , 2}$ do not vary in proportion to the relative areas of basal and edge surface sites on both minerals, suggesting that dual Langmuir behavior is not related to particle morphology but the presence of two different surface complexes (e.g., inner- and outer-sphere species) on both minerals. These macroscopic adsorption behaviors in the present study have also been observed in our previous study [22]. It should be noted that the very large $\mathrm{K}_{1}$ value in the dual Langmuir model fit for gibbsite at $\mathrm{pH} 7$ in $0.5 \mathrm{M} \mathrm{NaNO}_{3}$ is likely not determined uniquely because of the lack of adsorption data at very low arsenate concentration. This is reflected in the small value of $\Gamma_{\max , 1}$ and the large uncertainty in $\mathrm{K}_{1}$.
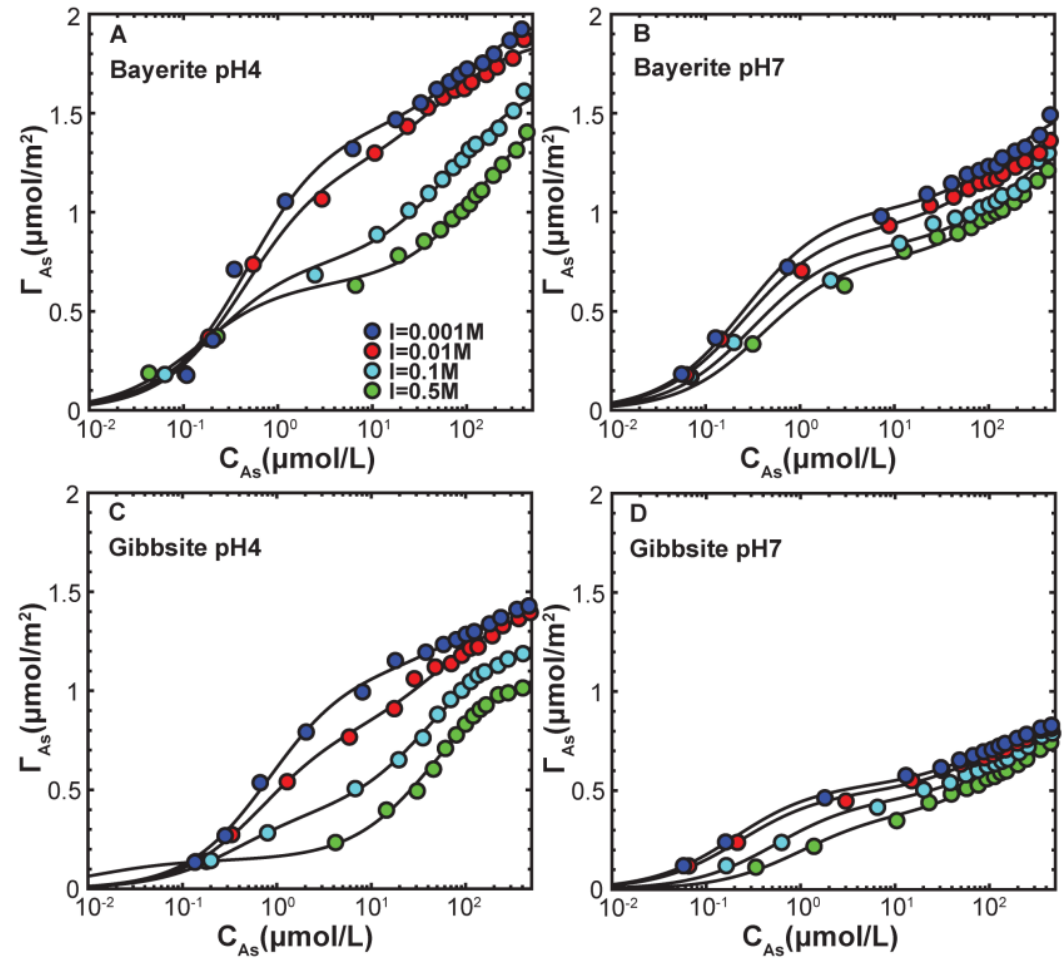

Figure 1. Arsenate adsorption isotherms as a function of ionic strength for bayerite at (A) $\mathrm{pH} 4$ and (B) $\mathrm{pH}$ 7, on gibbsite at (C) $\mathrm{pH} 4$ and (D) $\mathrm{pH}$ 7. Solids lines represent dual Langmuir isotherm fits to the data, with detailed fitting information provided in Table 2.

For each mineral, a change in ionic strength has substantial effects on arsenate uptake, with adsorption decreasing as ionic strength increases (Figure 1). These ionic strength-dependence effects on arsenate adsorption are larger in magnitude at $\mathrm{pH} 4$ and on bayerite (Figure 1). At $\mathrm{pH} 4$ the effect of ionic strength varies with final arsenate concentration $\left(\mathrm{C}_{\mathrm{As}}\right)$ : low $\mathrm{C}_{\mathrm{As}}(<0.3 \mu \mathrm{mol} / \mathrm{L})$ regions display little variation in uptake with ionic strength, intermediate conditions $\left(0.3 \mu \mathrm{mol} / \mathrm{L}<\mathrm{C}_{\mathrm{As}}<60 \mu \mathrm{mol} / \mathrm{L}\right)$ showed the greatest ionic strength effect, and high $\mathrm{C}_{\mathrm{As}}(>60 \mu \mathrm{mol} / \mathrm{L})$ regions showed a weaker ionic strength effect. In contrast, at $\mathrm{pH} 7$ the effect of ionic strength on adsorption appears uniform across all arsenate concentrations. These results display clear macroscopic signatures associated with the presence of outer-sphere species, i.e., a decrease in adsorption with increasing ionic strength. The smaller effect seen at $\mathrm{pH} 7$ may imply such species are of lower abundance under neutral conditions, but the magnitude of ionic strength effects on outer-sphere adsorption varies with the 
surface potential. If the surface charge is largely neutralized at $\mathrm{pH} 7$ by arsenate adsorption, then little to no effect of ionic strength, is expected even if outer-sphere species are present.

Table 2. Fitting parameters for dual Langmuir isotherms.

\begin{tabular}{|c|c|c|c|c|c|c|c|}
\hline Mineral & $\mathrm{pH}$ & I (M) & $\begin{array}{c}\Gamma_{\max , 1} \\
\left(\mu \mathrm{mol} / \mathrm{m}^{2}\right)\end{array}$ & $\mathrm{K}_{1}(\mathrm{~L} / \mu \mathrm{mol})$ & $\begin{array}{c}\Gamma_{\max , 2} \\
\left(\mu \mathrm{mol} / \mathrm{m}^{2}\right)\end{array}$ & $\mathrm{K}_{2}(\mathrm{~L} / \mu \mathrm{mol})$ & R-Factor ${ }^{a}$ \\
\hline \multirow{4}{*}{ Bayerite } & \multirow{4}{*}{4} & 0.5 & $0.64 \pm 0.03$ & $7.23 \pm 1.37$ & $0.98 \pm 0.05$ & $0.007 \pm 0.001$ & 0.020 \\
\hline & & 0.1 & $0.75 \pm 0.04$ & $4.83 \pm 0.89$ & $0.94 \pm 0.04$ & $0.014 \pm 0.003$ & 0.017 \\
\hline & & 0.01 & $1.24 \pm 0.06$ & $2.25 \pm 0.32$ & $0.65 \pm 0.06$ & $0.02 \pm 0.007$ & 0.019 \\
\hline & & 0.001 & $1.43 \pm 0.07$ & $2.11 \pm 0.32$ & $0.62 \pm 0.09$ & $0.0092 \pm 0.006$ & 0.022 \\
\hline \multirow{4}{*}{ Bayerite } & \multirow{4}{*}{7} & 0.5 & $0.77 \pm 0.03$ & $2.54 \pm 0.48$ & $0.62 \pm 0.08$ & $0.0054 \pm 0.002$ & 0.021 \\
\hline & & 0.1 & $0.83 \pm 0.04$ & $3.17 \pm 0.65$ & $0.59 \pm 0.13$ & $0.004 \pm 0.002$ & 0.026 \\
\hline & & 0.01 & $0.92 \pm 0.30$ & $3.86 \pm 0.47$ & $0.51 \pm 0.04$ & $0.01 \pm 0.003$ & 0.016 \\
\hline & & 0.001 & $1.02 \pm 0.03$ & $3.87 \pm 0.50$ & $0.60 \pm 0.07$ & $0.0056 \pm 0.002$ & 0.020 \\
\hline \multirow{4}{*}{ Gibbsite } & \multirow{4}{*}{4} & 0.5 & $0.15 \pm 0.03$ & $78.38 \pm 9.01$ & $0.99 \pm 0.03$ & $0.02 \pm 0.003$ & 0.022 \\
\hline & & 0.1 & $0.39 \pm 0.03$ & $2.74 \pm 0.60$ & $0.90 \pm 0.03$ & $0.023 \pm 0.002$ & 0.012 \\
\hline & & 0.01 & $0.81 \pm 0.05$ & $1.45 \pm 0.26$ & $0.63 \pm 0.05$ & $0.018 \pm 0.005$ & 0.018 \\
\hline & & 0.001 & $1.11 \pm 0.04$ & $1.21 \pm 0.11$ & $0.39 \pm 0.04$ & $0.0089 \pm 0.004$ & 0.013 \\
\hline \multirow{4}{*}{ Gibbsite } & \multirow{4}{*}{7} & 0.5 & $0.38 \pm 0.02$ & $1.02 \pm 0.21$ & $0.47 \pm 0.03$ & $0.0064 \pm 0.002$ & 0.020 \\
\hline & & 0.1 & $0.45 \pm 0.02$ & $1.85 \pm 0.26$ & $0.44 \pm 0.03$ & $0.0064 \pm 0.002$ & 0.018 \\
\hline & & 0.01 & $0.49 \pm 0.02$ & $4.39 \pm 0.62$ & $0.38 \pm 0.02$ & $0.011 \pm 0.003$ & 0.019 \\
\hline & & 0.001 & $0.53 \pm 0.01$ & $5.02 \pm 0.40$ & $0.36 \pm 0.01$ & $0.010 \pm 0.002$ & 0.010 \\
\hline
\end{tabular}

${ }^{a}$ Goodness-of-fit parameter. The R-factor is the sum of the differences between the data and the fit at each data point, divided by the sum of the data at each corresponding point. Smaller R-factor values reflect better fits.

\subsection{Ionic Strength Effect on Surface Charge Properties}

$\zeta$-potential measurements were made to evaluate how different background electrolyte concentrations affect surface charging, and thus trends in the surface potential of gibbsite and bayerite particles in the absence and presence of arsenate. Over the $\mathrm{pH}$ range studied, gibbsite and bayerite suspensions have positive $\zeta$-potential values in the absence of arsenate (Figure 2), consistent with previous studies of aluminum hydroxides with a typical isoelectric point (IEP) around $\mathrm{pH} 9-10$ [23,32-35]. At individual $\mathrm{pH}$ conditions, $\zeta$-potential for both minerals decreases with increasing ionic strength (Figure 2), consistent with the known effect of counterion screening of surface charge, reducing the potential at the shear plane. After arsenate loading, the $\zeta$-potential values of both minerals shift to more negative values, as expected for anion adsorption. For each mineral system, the $\zeta$-potential value is lower near $\mathrm{pH} 7$ than near $\mathrm{pH} 4$, indicating that the surface potential is also lower at $\mathrm{pH} 7$, and ionic strength-dependence effects on outer-sphere species are thus expected to be substantially greater at $\mathrm{pH} 4$ (Figure 2). The $\zeta$-potential appears to always be larger for bayerite than gibbsite in the presence of arsenate below $\mathrm{pH} 6$ (Figure 2), indicating that the bayerite systems should display stronger ionic strength effects at acidic conditions. These two features are consistent with the observations in adsorption isotherm experiments in this study. In addition, the IEP differs between the two minerals, occurring near $\mathrm{pH} 7$ for gibbsite at both arsenate coverages, but remaining above $\mathrm{pH} 8$ for bayerite except at the highest arsenate coverage (Figure 2). 

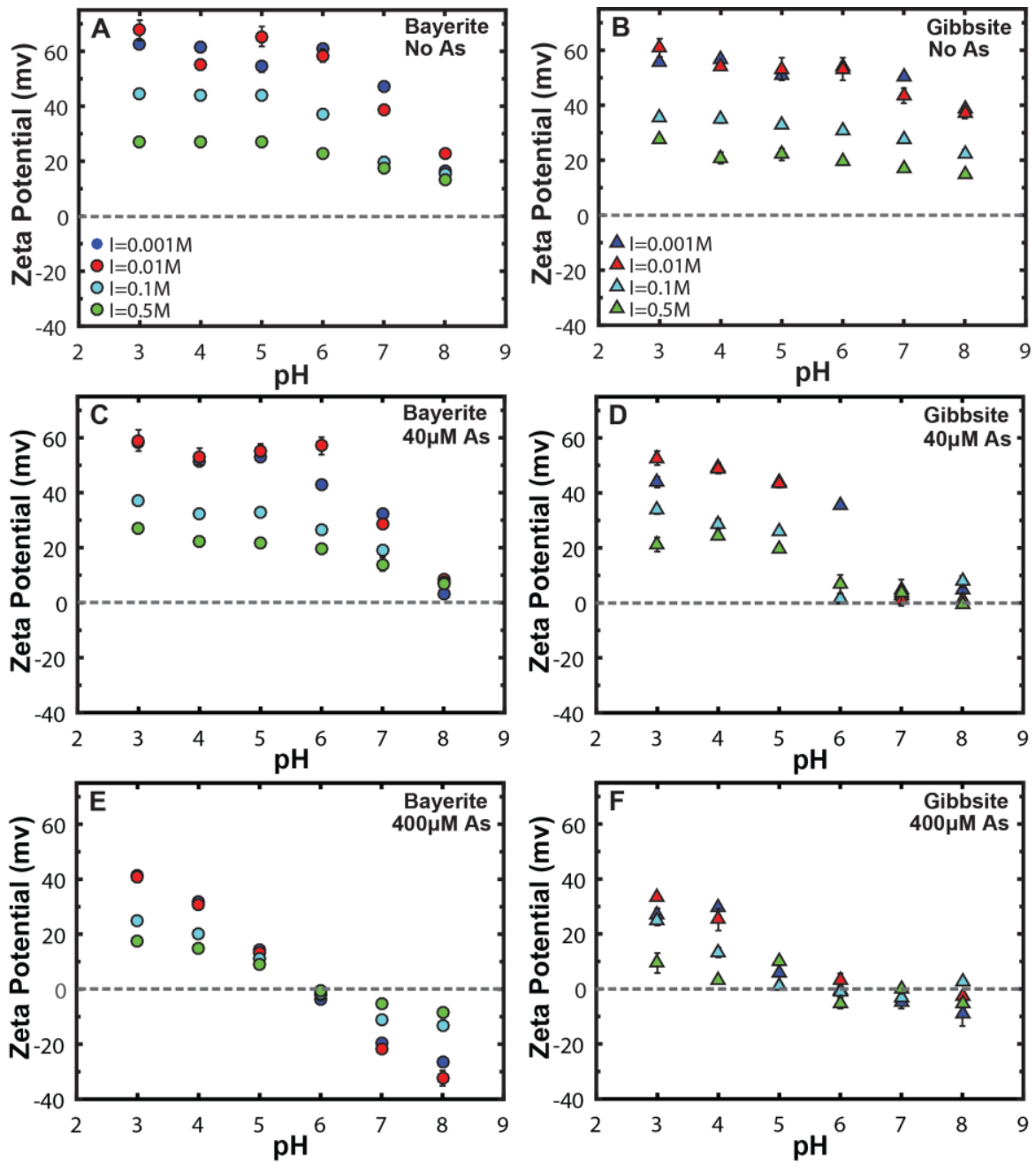

Figure 2. $\zeta$-potential as a function of $\mathrm{pH}$ for systems with no arsenate on bayerite (A) and gibbsite (B), $40 \mu \mathrm{M}$ arsenate on bayerite (C) and gibbsite (D), $400 \mu \mathrm{M}$ arsenate on bayerite (E) and gibbsite (F). The error bars represent the standard deviation of three replicate measurements.

\subsection{Arsenate Adsorption Mechanisms}

Arsenic surface speciation for a series of adsorption samples (Table 1) was characterized using EXAFS spectroscopy to determine the effect of ionic strength on arsenate binding mechanisms. Conditions are chosen to explore low and high arsenate surface loading at the highest and lowest electrolyte concentrations, 0.5 and $0.001 \mathrm{M} \mathrm{NaNO}_{3}$. Structural model fits of the EXAFS spectra yield interatomic distances of $\sim 3.2 \AA$ for As- $\mathrm{Al}$ shell for all samples regardless of $\mathrm{pH}$, ionic strength, arsenate coverage, and mineral sorbents (Figure 3, Table 3). This configuration corresponds to a bridging bidentate inner-sphere surface complex, as has been identified in most previous studies $[1,8,17,36,37]$. All spectra for each sample were fitted using a single starting structural model consisting of only one Al neighbor corresponding to this bidentate binding configuration. As noted in our prior study [22], we also evaluated whether monodentate species are present by adding a second As-Al path at R of 3.5 to $3.6 \AA$ in our initial model. However, this did not improve the quality of fit and resulted in a CN for this longer $\mathrm{Al}$ shell within an error of zero for all sample studied. This indicates that monodentate inner-sphere species are negligible on these minerals for all conditions examined.

The EXAFS-derived coordination number of $\mathrm{Al}$ neighbors associated with the inner-sphere complex on both minerals is less than 2 (Table 3), the expected value if all the adsorbed arsenate was in a bridging bidentate geometry. This could indicate the presence of outer-sphere arsenate complexes as 
other inner-sphere binding configurations were not observed under our experimental conditions [22]. Also, this coordination number of $\mathrm{Al}$ neighbors is lower on average on gibbsite than that on bayerite. It should be noted that $\mathrm{Al}$ coordination numbers obtained from individual samples are not statistically distinguishable because of the large fitting uncertainties. However, statistical tests ( $t$-tests), as applied in the prior study [22], showed that the difference in the average $\mathrm{Al}$ coordination numbers for two mineral sets is significant. The lower average $\mathrm{Al}$ coordination number on gibbsite indicates a greater proportion of outer-sphere complexes. For individual mineral system, similar statistical tests were performed to evaluate if the average $\mathrm{Al}$ coordination number of high ionic strength set differs from that of low ionic strength set. $t$-tests show that average $\mathrm{Al}$ coordination numbers are statistically invariant with different ionic strength for both minerals, suggesting that ionic strength has little effect on arsenate surface complexation geometry as well as the distribution of different types of arsenate surface species on gibbsite or bayerite.
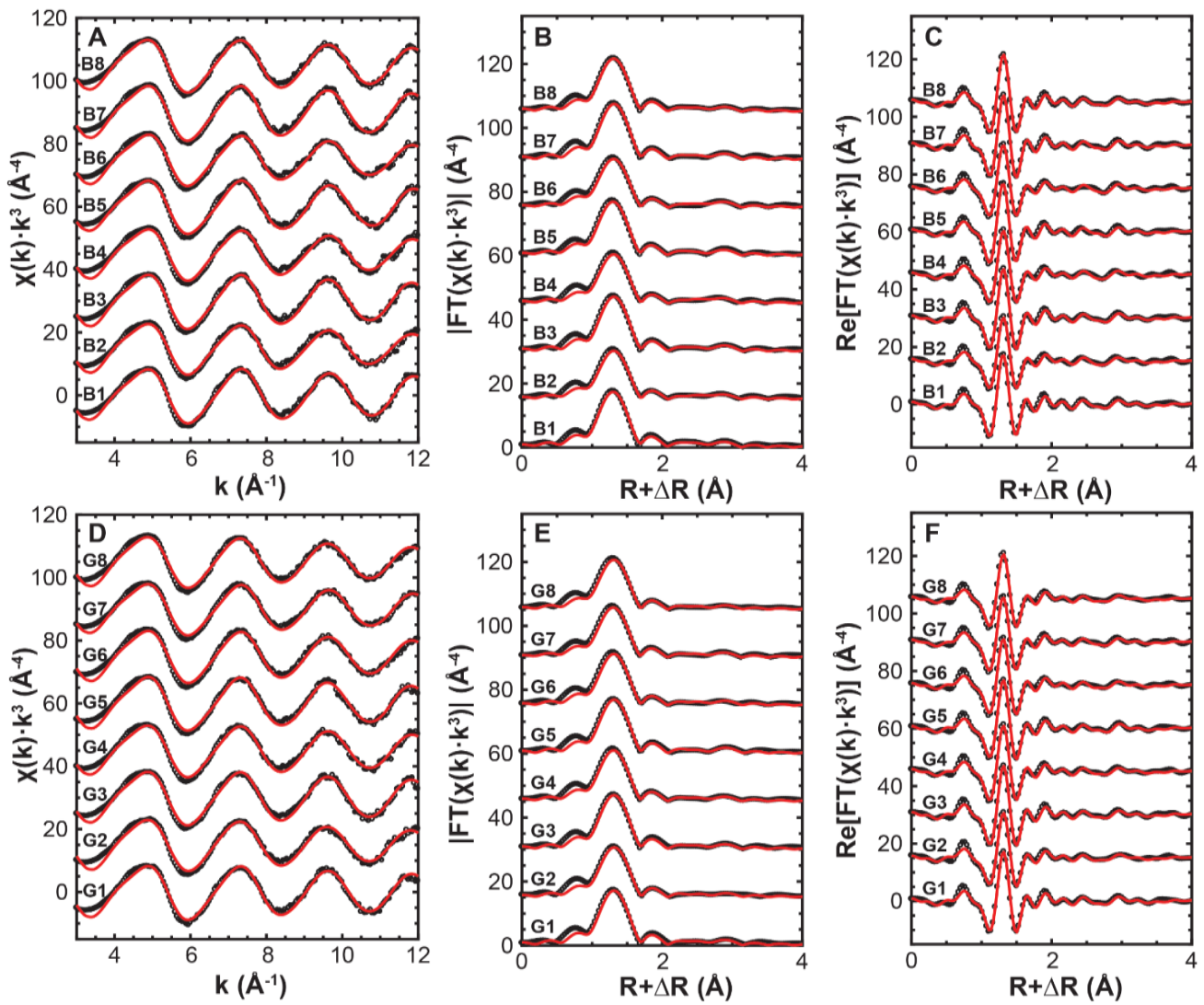

Figure 3. Data (dotted) and structural fits (solids) to the As K-edge spectra (A,D), Fourier transform magnitudes (B,E), and real components of the Fourier transforms $(\mathbf{C}, \mathbf{F})$ of the series of adsorption samples. Detailed sample information is provided in Table 1.

Table 3. As K-edge EXAFS fitting parameters.

\begin{tabular}{cccccccc}
\hline Sample & Path & $\mathbf{C N}^{\mathbf{a}}$ & $\mathbf{R}(\AA)^{\mathbf{b}}$ & $\boldsymbol{\sigma}^{2}\left(\AA^{2}\right)^{\mathbf{c}}$ & $\Delta \mathbf{E}_{\mathbf{0}}(\mathbf{e V})^{\mathbf{d}}$ & R-Factor $^{\mathbf{e}}$ & $\chi_{\mathbf{v}}{ }^{2} \mathbf{e}$ \\
\hline \multirow{2}{*}{ G1 } & As-O & 4 & $1.696(4)$ & $0.0019(2)$ & $7(1)$ & 0.008 & 37.70 \\
& As-Al & $0.9(5)^{\mathrm{f}}$ & $3.19(3)$ & 0.006 & & & \\
\hline \multirow{2}{*}{ G2 } & As-O & 4 & $1.701(4)$ & $0.0027(2)$ & $8(1)$ & 0.008 & 26.50 \\
& As-Al & $0.6(4)$ & $3.21(5)$ & 0.006 & & & \\
\hline \multirow{2}{*}{ G3 } & As-O & 4 & $1.697(4)$ & $0.0020(2)$ & $7(1)$ & 0.008 & 41.28 \\
& As-Al & $0.9(5)$ & $3.19(3)$ & 0.006 & & & \\
\hline
\end{tabular}


Table 3. Cont.

\begin{tabular}{|c|c|c|c|c|c|c|c|}
\hline Sample & Path & $\mathrm{CN}^{\mathrm{a}}$ & $R(\AA ̊) ~ b$ & $\sigma^{2}\left(\AA^{2}\right)^{c}$ & $\Delta \mathrm{E}_{0}(\mathrm{eV})^{\mathrm{d}}$ & R-Factor ${ }^{\mathrm{e}}$ & $x_{v}^{2}$ \\
\hline \multirow{2}{*}{ G4 } & As-O & 4 & $1.694(4)$ & $0.0024(2)$ & \multirow[t]{2}{*}{$6(1)$} & \multirow[t]{2}{*}{0.011} & \multirow[t]{2}{*}{49.88} \\
\hline & As-Al & $0.8(5)$ & $3.19(4)$ & 0.006 & & & \\
\hline \multirow{2}{*}{ G5 } & As-O & 4 & $1.697(3)$ & $0.0021(3)$ & \multirow[t]{2}{*}{$8(1)$} & \multirow[t]{2}{*}{0.007} & \multirow[t]{2}{*}{20.25} \\
\hline & As-Al & $1.1(4)$ & $3.22(3)$ & 0.006 & & & \\
\hline \multirow{2}{*}{ G6 } & As-O & 4 & $1.696(5)$ & $0.0024(5)$ & \multirow[t]{2}{*}{$7(1)$} & \multirow[t]{2}{*}{0.013} & \multirow[t]{2}{*}{58.38} \\
\hline & As-Al & $0.8(6)$ & $3.19(5)$ & 0.006 & & & \\
\hline \multirow{2}{*}{ G7 } & As-O & 4 & $1.690(5)$ & $0.0026(2)$ & \multirow[t]{2}{*}{$6(1)$} & \multirow[t]{2}{*}{0.012} & \multirow[t]{2}{*}{62.78} \\
\hline & As-Al & $1.0(5)$ & 3.18 (4) & 0.006 & & & \\
\hline \multirow{2}{*}{ G8 } & As-O & 4 & $1.698(5)$ & $0.0027(2)$ & \multirow[t]{2}{*}{$7(1)$} & \multirow[t]{2}{*}{0.012} & \multirow[t]{2}{*}{32.16} \\
\hline & As-Al & $0.7(5)$ & $3.21(5)$ & 0.006 & & & \\
\hline \multirow{2}{*}{ B1 } & As-O & 4 & $1.686(4)$ & $0.0018(2)$ & \multirow[t]{2}{*}{$5(1)$} & \multirow[t]{2}{*}{0.009} & \multirow[t]{2}{*}{42.92} \\
\hline & As-Al & $1.2(5)$ & 3.18 (3) & 0.006 & & & \\
\hline \multirow{2}{*}{ B2 } & As-O & 4 & $1.697(5)$ & $0.0028(5)$ & \multirow[t]{2}{*}{$7(1)$} & \multirow[t]{2}{*}{0.013} & \multirow[t]{2}{*}{27.54} \\
\hline & As-Al & $1.1(5)$ & $3.17(3)$ & 0.006 & & & \\
\hline \multirow{2}{*}{ B3 } & As-O & 4 & $1.696(4)$ & 0.0019 (2) & \multirow[t]{2}{*}{$7(1)$} & \multirow[t]{2}{*}{0.007} & \multirow[t]{2}{*}{34.56} \\
\hline & As-Al & $1.2(4)$ & $3.20(3)$ & 0.006 & & & \\
\hline & As-O & 4 & $1.696(5)$ & $0.0027(3)$ & $7(1)$ & 0.013 & 73.71 \\
\hline B4 & As-Al & $1.2(5)$ & $3.17(3)$ & 0.006 & & & \\
\hline & As-O & 4 & $1.686(5)$ & $0.0020(2)$ & $5(1)$ & 0.011 & 56.60 \\
\hline B5 & As-Al & $1.2(6)$ & $3.19(3)$ & 0.006 & & & \\
\hline & As-O & 4 & $1.695(5)$ & $0.0028(2)$ & $7(1)$ & 0.012 & 75.51 \\
\hline B6 & As-Al & $1.4(5)$ & $3.18(3)$ & 0.006 & & & \\
\hline & As-O & 4 & $1.697(4)$ & $0.0018(2)$ & $7(1)$ & 0.007 & 37.21 \\
\hline B7 & As-Al & $1.2(5)$ & 3.19 (3) & 0.006 & & & \\
\hline & As-O & 4 & $1.694(3)$ & $0.0021(2)$ & $6(1)$ & 0.006 & 20.21 \\
\hline B8 & As-Al & $1.1(4)$ & $3.18(3)$ & 0.006 & & & \\
\hline
\end{tabular}

${ }^{a}$ Coordination number. ${ }^{b}$ Interatomic distance. ${ }^{c}$ Debye-Waller factor. ${ }^{\mathrm{d}}$ Difference in the threshold Fermi level between the data and theory. ${ }^{\mathrm{e}}$ Goodness-of-fit parameters [38]. ${ }^{\mathrm{f}}$ The estimated standard deviations are listed in parentheses, representing the errors in the last digit.

\section{Discussion}

\subsection{Implications to Arsenate Adsorption Mechanisms}

Our macroscopic and spectroscopic measurements on aluminum hydroxide powders, together with the previous surface scattering study of arsenate adsorbed on aluminum and iron oxide single crystal surfaces [21], now provide a generally self-consistent description of arsenate adsorption, indicating that inner- and outer-sphere arsenate species co-adsorb over a wide range of surface coverages and $\mathrm{pH}$. Arsenate adsorption does show the classical dependence on ionic strength, with a substantial effect when the surface potential is large and a negligible effect when the surface potential is near zero. All of these observations are the expected macroscopic behaviors when outer-sphere arsenate surface complexes are present.

However, these results also reveal unexpected observations. The decrease in arsenate adsorption with increasing ionic strength in the isotherms is expected to reduce the fraction of adsorbed arsenate that occurs as an outer-sphere complex, but no clear trend in the coordination number of second shell Al neighbors with increasing ionic strength was observed in EXAFS spectroscopy. This may be because the uncertainty in EXAFS-derived coordination numbers (typically \pm 0.5 ) is too large to observe the expected trends with the number of analyses available. Alternatively, other aspects of the adsorption process may be affected by ionic strength in ways that do not substantially change the balance of inner- 
and outer-sphere species. For example, a prior study using the extended triple-layer model suggested a possible reaction stoichiometry involving both inner- and outer-sphere arsenate species in a ratio independent of $\mathrm{pH}$ and surface coverage and only sensitive to the activity of water [39]. Alternatively, if applying a charge distribution model then inner-sphere complexes have two $\mathrm{O}$ ligands extending to the $\beta$-plane, producing an ionic strength-dependence on macroscopic uptake [19]. While this would be weaker in magnitude than for outer-sphere species, the reduction in surface coverage combined with the EXAFS fitting uncertainties may be adequate to explain the apparent lack of change in the distribution of arsenate surface species. More broadly, the ratio of inner- to outer-sphere arsenate species appears to be stable across a wide range of surface coverages [21,22], $\mathrm{pH}$ values [22], and salt contents. Reaction stoichiometries that reproduce this phenomenon need to be investigated in future refinements of surface complexation models.

A separated feature of note in the results is an apparent correlation of the Dual Langmuir model fitting parameters (i.e., $\mathrm{K}$ and $\Gamma_{\max }$ values) and ionic strength (Table 2). $\Gamma_{\max , 1}$ values decrease with increasing ionic strength for both minerals at both $\mathrm{pH}$ conditions, with a weaker variation at $\mathrm{pH}$ 7 (Figure S2A). $\mathrm{K}_{1}$ values show distinct behaviors at the two $\mathrm{pH}$ values studied, increasing with increasing ionic strength at $\mathrm{pH} 4$ but decrease at $\mathrm{pH} 7$ (Figure S2C). In contrast, $\Gamma_{\max , 2}$ and $\mathrm{K}_{2}$ values display little variation as ionic strength changes for all conditions (Figure S2B,D). If the distinct strong and weak correlations of $K_{1}$ and $K_{2}$ with ionic strength originated from $K_{1}$ attributed to inner-sphere adsorption and $K_{2}$ attributed to outer-sphere adsorption, a change in the population of inner- and outer-sphere species with increasing ionic strength and arsenate surface coverage should occur. However, as noted above this is not observed in our EXAFS results. The origin of the effects of ionic strength on the dual Langmuir isotherm components is thus uncertain. Many factors can induce variations in $\mathrm{K}$ values, including changes in activity coefficients for the dissolved species, surface site competition with electrolyte ions, $\mathrm{Na}-\mathrm{AsO}_{4}$ complexation in solution, and changes in surface potential as ionic strength and arsenate surface coverage increases. Thus, the observed trends in $\mathrm{K}$ with ionic strength are most likely attributed to multiple origins instead of a single origin. The smaller difference in $\Gamma_{\max , 1}$ seen at $\mathrm{pH} 7$ compared to $\mathrm{pH} 4$ may be dominantly controlled by the difference in surface potential (large surface potential at $\mathrm{pH} 4$ and small to zero one at $\mathrm{pH} 7$ ) but also may be affected by changes in solution speciation and $\mathrm{Na}^{+}$and $\mathrm{NO}_{3}{ }^{-}$interactions with mineral surfaces. However, the spectroscopic results clearly rule out the strongly (Langmuir isotherm 1) and weakly (Langmuir isotherm 2) bound arsenate species corresponding to inner- and outer-sphere complexes. The coexistence of such species is surprisingly unrelated to the apparent adsorption isotherm behavior. Surface complexation models are needed to identify the aspects of the observed variations in uptake behaviors with increasing ionic strength that are induced by activity corrections, solution complexation, surface site competition, and surface potential changes.

\subsection{Implications to Arsenate in the Environment}

The strong adsorption of arsenate to many aluminum and iron (hydro)oxide minerals widely observed in past studies $[8,9,12,13,17]$ has traditionally been attributed solely inner-sphere surface complexes. However, the co-adsorption of inner- and outer-sphere arsenate species indicates that the latter species are partially responsible for this strong adsorption behavior. While such species appear to have high affinity for the mineral surface, they are expected to be more kinetically labile because of their adsorption-desorption does not involve ligand exchange. This suggests that they may desorb more rapidly from mineral surfaces than inner-sphere species, although experimental confirmation is needed as desorption of outer-sphere species was recently shown to be the rate-limiting step in overall $\mathrm{Rb}^{+}$desorption on muscovite [40]. Past macroscopic kinetic studies for arsenate have often observed two-stage (i.e., fast and slow) desorption from powder substrates [41-44] and the fast component may be attributable to the outer-sphere species suggested in the current work. Arsenate adsorption behavior is thus more complex than previously recognized, with inner- and outer-sphere surface complexes displaying similar adsorption affinities and co-occurring over a wide range of conditions. 
The present work highlights a clear relationship between ionic strength and arsenate adsorption behavior on aluminum hydroxides that may affect arsenate mobility in natural systems under various geochemical conditions. A diverse set of environments can generate an increase in ionic strength: suspended particles in rivers entering the ocean, saltwater intrusion into an aquifer, brines released during hydrocarbon exploration or geologic $\mathrm{CO}_{2}$ sequestration, and soils and streams exposed to road salt. Arsenate desorption from particles may thus occur in all cases, although the present work suggests it would be most substantial under weakly acidic conditions, such as in soils, and may be negligible in neutral to alkaline groundwater and seawater. The present work thus identifies an unrecognized process to potentially mobilize arsenic in environmental and geological systems.

Supplementary Materials: The following are available online at www.mdpi.com/2411-5126/2/1/s1, Figure S1: Single Langmuir isotherm fits to arsenate adsorption in different ionic strength on bayerite and gibbsite $\mathrm{pH} 4$ and pH 7, Figure S2: Correlations of dual Langmuir fitting parameters versus square root of ionic strength, Table S1: Fitting parameters for Single Langmuir isotherms.

Acknowledgments: This research was supported by the U.S. National Science Foundation (NSF) Environmental Chemical Sciences program through award No. CHE-1505532. $\zeta$-potential analyses were conducted at the Nano Research Facility at Washington University in St. Louis, supported by the NSF through award No. ECS-00335765. EXAFS spectra were collected at beamline 4-1 at the SSRL, operated by SLAC National Accelerator Laboratory with support from the U.S. Department of Energy (DOE) Office of Science through Contract No. DE-AC02-76SF00515. The authors would like to thank Ryan Davis for beamline support.

Author Contributions: Tingying $\mathrm{Xu}$ conceived, designed, and performed the experiments with support from Jeffrey G. Catalano; Tingying Xu and Jeffrey G. Catalano worked together to analyze the data; Tingying Xu wrote the paper with edits from Jeffrey G. Catalano. Both authors read and approved the content.

Conflicts of Interest: The authors declare no conflict of interest.

\section{References}

1. Foster, A.L.; Brown, G.E.; Tingle, T.N.; Park, G.A. Quantitative arsenic speciation in mine tailings using X-ray absorption spectroscopy. Am. Miner. 1998, 83, 553-568. [CrossRef]

2. Jain, C.K.; Ali, I. Arsenic: Occurrence, toxicity and speciation techniques. Water Res. 2000, 34, 4304-4312. [CrossRef]

3. Mandal, B.K.; Suzuku, K.T. Arsenic around the world: A review. Talanta 2003, 58, 201-235. [CrossRef]

4. Arai, Y.; Lanzirotti, A.; Sutton, S.; Davis, J.A.; Sparks, D.L. Arsenic speciation and reactivity in poultry litter. Environ. Sci. Technol. 2003, 37, 4083-4090. [CrossRef] [PubMed]

5. Smedley, P.L.; Kinniburgh, D.G. A review of the source, behavior and distribution of arsenic in natural waters. Appl. Geochem. 2002, 17, 517-568. [CrossRef]

6. Chwirka, J.D.; Thomson, B.M.; Stomp, J.M. Removing arsenic from groundwater. J. Am. Water Works Assoc. 2000, 92, 79-88.

7. Garelick, H.; Dybowska, A.; Valsami-Jones, E.; Priest, N.D. Remediation technologies for arsenic contaminated drinking waters. J. Soils Sediments 2005, 5, 182-190. [CrossRef]

8. Arai, Y.; Elzinga, E.J.; Sparks, D.L. X-ray absorption spectroscopic investigation of arsenite and arsenate adsorption at the aluminum oxide-water interface. J. Colloid Interface Sci. 2001, 235, 80-88. [CrossRef] [PubMed]

9. Goldberg, S.; Johnston, C.T. Mechanisms of arsenic adsorption on amorphous oxides evaluated using macroscopic measurements, vibrational spectroscopy, and surface complexation modeling. J. Colloid Interface Sci. 2001, 234, 204-216. [CrossRef] [PubMed]

10. Antelo, J.; Avena, M.; Fiol, S.; Lopez, R.; Arce, F. Effects of pH and ionic strength on the adsorption of phosphate and arsenate at the goethite-water interface. J. Colloid Interface Sci. 2005, 285, 476-486. [CrossRef] [PubMed]

11. Hayes, K.F.; Papelis, C.; Leckie, J.O. Modeling ionic strength effects of anion adsorption at hydrous oxide/solution interface. J. Colloid Interface Sci. 1988, 125, 717-726. [CrossRef]

12. Manceau, A. The mechanism of anion adsorption on iron oxides: Evidence for the bonding of arsenate tetrahedra on free $\mathrm{Fe}(\mathrm{O}, \mathrm{OH})_{6}$ edges. Geochim. Cosmochim. Acta 1995, 59, 3647-3653. [CrossRef] 
13. Fendorf, S.; Eick, M.J.; Grossl, P.; Sparks, D.L. Arsenate and chromate retention mechanisms on goethite. 1. Surface structure. Environ. Sci. Technol. 1997, 31, 315-320. [CrossRef]

14. Lumsdon, D.G.; Fraser, A.R.; Russell, J.D.; Livesey, N.T. New infrared band assignments for the arsenate ion adsorbed on synthetic goethite ( $\alpha$-FeOOH). J. Soil Sci. 1984, 35, 381-386. [CrossRef]

15. Sun, X.; Doner, H.E. An investigation of arsenate and arsenite bonding structures on goethite by FTIR. Soil Sci. 1996, 161, 865-872. [CrossRef]

16. Myneni, S.C.B.; Traina, S.J.; Waychunas, G.A.; Logan, T.J. Experimental and theoretical vibrational spectroscopic evaluation of arsenate coordination in aqueous solutions, solids, and at mineral-water interfaces. Geochim. Cosmochim. Acta 1998, 62, 3285-3300. [CrossRef]

17. Waychunas, G.A.; Rea, B.A.; Fuller, C.C.; Davis, J.A. Surface chemistry of ferrihydrite: Part 1. EXAFS studies of the geometry of coprecipitated and adsorbed arsenate. Geochim. Cosmochim. Acta 1993, 57, 2251-2269. [CrossRef]

18. Goldberg, S. Chemical modeling of arsenate adsorption on aluminum and iron oxide minerals. Soil Sci. Soc. Am. J. 1986, 50, 1154-1157. [CrossRef]

19. Hiemstra, T.; Van Riemsdijk, W.H. Surface structural ion adsorption modeling of competitive binding of oxyanions by metal (hydr)oxides. J. Colloid Interface Sci. 1999, 210, 182-193. [CrossRef] [PubMed]

20. Dixit, S.; Hering, J.G. Comparison of arsenic(V) and arsenic(III) sorption onto iron oxide minerals: Implications for arsenic mobility. Environ. Sci. Technol. 2003, 37, 4182-4189. [CrossRef] [PubMed]

21. Catalano, J.G.; Park, C.; Fenter, P.; Zhang, Z. Simultaneous inner- and outer-sphere arsenate complexation on corundum and hematite. Geochim. Cosmochim. Acta 2008, 72, 1986-2004. [CrossRef]

22. Xu, T.; Catalano, J.G. Impacts of surface site coordination on arsenate adsorption: Macroscopic uptake and binding mechanisms on aluminum hydroxide surfaces. Langmuir 2016, 32, 13261-13269. [CrossRef] [PubMed]

23. Hiemstra, T.; Yong, H.; van Riemsdijk, W.H. Interfacial charging phenomena of aluminum (hydr)oxides. Langmuir 1999, 15, 5942-5955.

24. Shen, S.; Chow, P.S.; Chen, F.; Feng, S.; Tan, R.B.H. Synthesis of submicron gibbsite platelets by organic-free hydrothermal crystallization process. J. Cryst. Growth 2006, 292, 136-142. [CrossRef]

25. Lefevre, G.; Fedoroff, M. Synthesis of bayerite $\left[\beta-\mathrm{Al}(\mathrm{OH})_{3}\right]$ microrods by neutralization of alyminate ions at constant pH. Mater. Lett. 2002, 56, 978-983. [CrossRef]

26. Ravel, B.; Newville, M. ATHENA, ARTEMIS, HEPHAESTUS: Data analysis for X-ray absorption spectroscopy using IFEFFIT. J. Synchrotron Radiat. 2005, 12, 537-541. [CrossRef] [PubMed]

27. Newville, M. IFEFFIT: Interactive EXAFS analysis and FEFF fitting. J. Synchrotron Radiat. 2001, 8, 322-324. [CrossRef] [PubMed]

28. Webb, S.M. SixPack: A graphical user interface for XAS analysis using IFEFFIT. Phys. Scr. 2005, 115, 1011-1014. [CrossRef]

29. Harrison, W.T.A. Synthetic mansfieldite, $\mathrm{AlAsO}_{4} \cdot 2 \mathrm{H}_{2} \mathrm{O}$. Acta Cryst. 2000, 56, 421. [CrossRef]

30. Ankudinov, A.L.; Rehr, J.J. Relativistic calculations of independent X-ray absorption spectra. Phys. Rev. B 1997, 56, 1712-1715. [CrossRef]

31. Mikutta, C.; Frommer, J.; Voegelin, A.; Kaegi, R.; Kretzschmar, R. Effect of citrate on the local Fe coordination in ferrihydrite, arsenate binding, and ternary arsenate complex formation. Geochim. Cosmochim. Acta 2010, 74, 5574-5592. [CrossRef]

32. Rosenqvist, J.; Persson, P.; Sjoberg, S. Protonation and charging of nanosized gibbsite $\left[\alpha-\mathrm{Al}(\mathrm{OH})_{3}\right]$ particles in aqueous suspension. Langmuir 2002, 18, 4598-4604. [CrossRef]

33. Gan, Y.; Franks, G.V. Charging behavior of the gibbsite (001) surface in $\mathrm{NaCl}$ solution investigated by AFM colloidal probe technique. Langmuir 2006, 22, 6087-6092. [CrossRef] [PubMed]

34. Adekola, F.; Fedoroff, M.; Geckeis, H.; Kupcik, T.; Lefevre, G.; Lutzenkirchen, J.; Plaschke, M.; Preocanin, T.; Rabung, T.; Schild, D. Characterization of acid-base properties of two gibbsite samples in the context of literature results. J. Colloid Interface Sci. 2011, 354, 306-317. [CrossRef] [PubMed]

35. Manning, B.A.; Goldberg, S. Modeling Competitive Adsorption of arsenate with phosphate and molybdate on oxide minerals. Soil Sci. Soc. Am. J. 1996, 60, 121-131. [CrossRef]

36. Ladeira, A.C.Q.; Ciminelli, V.S.T.; Duarte, H.A.; Alives, M.C.M.; Ramos, A.Y. Mechanism of anion retention from EXAFS and density functional calculations: Arsenic(V) adsorbed on gibbsite. Geochim. Cosmochim. Acta 2001, 65, 1211-1217. [CrossRef] 
37. Kappen, P.; Webb, J. An EXAFS study of arsenic bonding on amorphous aluminum hydroxide. Appl. Geochem. 2013, 31, 79-83. [CrossRef]

38. Kelly, S.D.; Hesterberg, D.; Ravel, B. Analysis of soils and minerals using X-ray absorption spectroscopy. In Methods of Soil Analysis, Part 5-Mineralogical Methods; Ulery, A.L., Drees, L.R., Eds.; Soil Science Society of American: Madison, WI, USA, 2008; pp. 387-463.

39. Fukushi, K.; Sverjensky, D.A. A predictive model (ETLM) for arsenate adsorption and surface speciation on oxides consistent with spectroscopic and theoretical molecular evidence. Geochim. Cosmochim. Acta 2007, 71, 3717-3745. [CrossRef]

40. Lee, S.S.; Fenter, P.; Nagy, K.L.; Sturchio, N.C. Real-time observation of cation exchange kinetics and dynamics at the muscovite-water interface. Nat. Commun. 2017, 8, 15826. [CrossRef] [PubMed]

41. O'Reilly, S.E.; Strawn, D.G.; Sparks, D.L. Residence time effects on arsenate adsorption/desorption mechanisms on goethite. Soil Sci. Soc. Am. J. 2001, 65, 67-77. [CrossRef]

42. Quaghebeur, M.; Rate, A.; Rengel, Z.; Hinz, C. Desorption kinetics of arsenate from kaolinite as influenced by pH. J. Environ. Qual. 2005, 34, 479-486. [PubMed]

43. Arai, Y.; Spark, D.L. Residence time effects on arsenate surface speciation at the aluminum oxide-water interface. Soil Sci. 2002, 167, 303-314. [CrossRef]

44. Pigna, M.; Krishnamurti, G.S.R.; Violante, A. Kinetics of arsenate sorption-desorption from metal oxides: Effect of residence time. Soil Sci. Soc. Am. J. 2006, 70, 2017-2027. [CrossRef]

(C) 2018 by the authors. Licensee MDPI, Basel, Switzerland. This article is an open access article distributed under the terms and conditions of the Creative Commons Attribution (CC BY) license (http://creativecommons.org/licenses/by/4.0/). 